\title{
Adaptation and validation of Richmond Compulsive Buying Scale in Chinese population
}

\author{
SIMON CHING LAM ${ }^{1}$, ZOE SZE-LONG CHAN ${ }^{2}$, ANDY CHUN-YIN CHONG ${ }^{2}$, WENDY WING-CHI WONG ${ }^{2}$ and JIAWEN YE ${ }^{3}$ \\ ${ }^{1}$ School of Nursing, The Hong Kong Polytechnic University, Kowloon, Hong Kong SAR \\ ${ }^{2}$ School of Nursing and Health Studies, The Open University of Hong Kong, Kowloon, Hong Kong SAR \\ ${ }^{3}$ Department of Applied Psychology, Lingnan University, New Territories, Hong Kong SAR
}

(Received: April 15, 2018; revised manuscript received: August 11, 2018; accepted: August 14, 2018)

\begin{abstract}
Background and aims: Compulsive buying (CB) is a behavioral addiction that is conceptualized as an obsessivecompulsive and impulsive-control disorder. The Richmond Compulsive Buying Scale (RCBS), a six-item selfreporting instrument that has been validated worldwide, was developed based on this theoretical background. This study aimed to adapt RCBS to the Chinese population (RCBS-TC) to guide future national and international prevalence studies. Methods: This methodological study was conducted in two phases. Phase 1 involved the forward and backward translation of RCBS, the content and face validation of the RCBS, and the evaluation of its translation adequacy. Phase 2 involved the psychometric testing of RCBS-TC for its internal consistency, stability, and construct validity using confirmatory factor analysis (CFA). Results: In Phase 1, RCBS-TC obtained satisfactory item-level $(\mathrm{I}-\mathrm{CVI}=83.3 \%-100 \%)$ and scale-level content validity index $(\mathrm{CVI} / \mathrm{AVE}=97.2 \%)$, comprehensibility $(100 \%)$, and translation adequacy [intraclass correlation coefficient $($ ICC $)=0.858$ ]. In Phase 2 , based on data collected from 821 adults, RCBS-TC demonstrated a satisfactory internal consistency (Cronbach's $\alpha=.88$; corrected item-total correlation coefficients $=0.61-0.78)$ 2-week test-retest reliability (ICC $=0.82$ based on 61 university students). For construct validation, the CFA results indicated that the corrected first-order two-factor models were acceptable with the same goodness-of-fit indices $\left(\chi^{2} / d f=8.56, \mathrm{CFI}=0.99, \mathrm{NFI}=0.98, \mathrm{IFI}=0.99\right.$, and RMSEA $\left.=0.09\right)$. The 2 -week test-retest reliability of RCBS-TC $(n=61)$ was also satisfactory (ICC $=0.82)$. Discussion and conclusions: This methodological study adopted appropriate and stringent procedures to ensure that the translation and validation of RCBS-TC was of quality. The results indicate that this scale has a satisfactory reliability and validity for the Chinese population.
\end{abstract}

Keywords: adaptation, translation, compulsive buying, behavioral addiction, psychometric testing, Chinese

\section{COMPULSIVE BUYING}

Although several studies have highlighted the severe negative outcomes caused by compulsive buying (CB), the fifth edition of the Diagnostic and Statistical Manual of Mental Disorders as well as the International Statistical Classification of Diseases and Related Health Problems 10th Revision do not consider $\mathrm{CB}$ a disorder due to insufficient empirical research in this field. Nevertheless, researchers continue to define $\mathrm{CB}$ as a behavioral addiction (Maraz et al., 2015; Rose \& Dhandayudham, 2014; Starcke, Schlereth, Domass, Schöler, \& Brand, 2013). According to the expanded conceptualization and theoretical classification of $\mathrm{CB}$ by Ridgway, Kukar-Kinney, and Monroe (2008), CB is embedded with two elements, namely, obsessive-compulsive and impulsive-control disorders (OCD and ICD, respectively). These schools of thought have received equal support and evidence from the literature regarding the development and maintenance of addictive behaviors (Everitt \& Robbins, 2016; Koob \& Volkow, 2016), role of impulsivity and compulsivity factors in $\mathrm{CB}$ behaviors (CBB; Billieux, Rochat, Rebetez, \& Van der Linden, 2008; Yi, 2013), and characteristics of CB (Black, 2007; Christenson et al., 1994; Yi, 2013). Thus, CB is defined as " a consumer's tendency to be preoccupied with buying that is revealed through repetitive buying and a lack of impulse control over buying" (Ridgway et al., 2008, p. 622). Indeed, compulsive buyers demonstrate anxiety disorders with obsessive thoughts and compulsive behaviors that cause distress and disturbance to their daily functioning. Moreover, compulsive buyers lack control over their urge to purchase (Billieux et al., 2008; Christenson et al., 1994).

The general population often underestimates the consequences of CBB. Based on an examination of 24 individuals with CBB, Christenson et al. (1994) noted that excessive buying leads to large debts (58\%), guilt (46\%), inability to meet payments $(42 \%)$, criticism from acquaintances $(33 \%)$, and criminal or legal problems (8\%). Furthermore, persons

\footnotetext{
* Corresponding author: Simon Ching Lam, PhD, RN, Assistant Professor; GH523, School of Nursing, The Hong Kong Polytechnic University, Hung Hom, Kowloon, Hong Kong SAR; Phone: +852 2766 5620; Fax: +852 2364 9663; E-mails: simlc@alumni. cuhk.net; simon.c.lam@polyu.edu.hk
}

This is an open-access article distributed under the terms of the Creative Commons Attribution-NonCommercial 4.0 International License, which permits unrestricted use, distribution, and reproduction in any medium for non-commercial purposes, provided the original author and source are credited, a link to the CC License is provided, and changes - if any - are indicated. 
with $\mathrm{CBB}$ often have an increasing level of urge or anxiety and can only feel a sense of completion when they make a purchase (Billieux et al., 2008; Black, 2007; Yi, 2013).

Despite its dire consequences, the prevalence of $\mathrm{CB}$ was only investigated in three population-based studies (excluding those studies that use student samples because of their limited representativeness) over the past decade. These studies recorded $\mathrm{CB}$ prevalence rates of $5.8 \%, 6.9 \%$, and $7.1 \%$ in their 2,153 American, 2,350 German, and 2,159 Galician samples, respectively (Koran, Faber, Aboujaoude, Large, \& Serpe, 2006; Mueller et al., 2010; Otero-López \& Villardefrancos, 2014). Furthermore, a recent meta-analysis showed that the 10,102 participants of eight adult representative studies on $\mathrm{CBB}$ had pooled $\mathrm{CB}$ prevalence rates ranging from $3.4 \%$ to $6.9 \%$ (mean $=4.9 \%$ ) (Maraz, Griffiths, \& Demetrovics, 2016). According to this meta-analysis in 2016, there was a lack of adult representative data in China and Taiwan. Instead, the prevalence of $\mathrm{CB}$ of adult nonrepresentative data (e.g., university staff and students) in these two Chinese societies was inconsistent (ranged from $6.7 \%$ to $29.8 \%$; Li, Unger, \& Bi, 2014; Lo \& Harvey, 2014; Wang \& Yang, 2008) but notably higher than the average CB prevalence rate $(4.9 \%)$. Such a higher-than-average result deserved an attention to the $\mathrm{CBB}$ of Chinese population. Nevertheless, the instruments used in these studies widely varied and seldom incorporated OCD and ICD to assess $\mathrm{CBB}$, thereby affecting their calculation of $\mathrm{CB}$ prevalence rates. An accurate estimation of $\mathrm{CB}$ prevalence rates will help highlight the impact of such behavior on public mental health (Koran et al., 2006; Maraz et al., 2016). Finding treatments for $\mathrm{CBB}$ is also especially important for those regions with substantially high $\mathrm{CB}$ prevalence rates.

The Richmond Compulsive Buying Scale (RCBS), which conceptualizes $\mathrm{CB}$ as a disorder with elements of impulsivity and compulsivity, was developed based on the theoretical classification of $\mathrm{CB}$ as an obsessive-compulsive spectrum disorder in 2008 (Ridgway et al., 2008). This scale uses an emerging theory from psychiatric literature that incorporates both obsessive-compulsive and impulsivecontrol dimensions (Billieux et al., 2008; Paula et al., 2015; Ridgway et al., 2008; Yi, 2013). Furthermore, RCBS emphasized the underlying $\mathrm{CB}$ tendency (independence of income or money-related demographic characteristics) but not the consequences of CB (i.e., income-dependent characteristics that check the overspending behaviors can be considered as part of the nomological network; Ridgway et al., 2008). These features make RCBS appropriate in measuring the $\mathrm{CB}$ in both developing and developed countries and hence facilitate the cross-cultural adaptation. Six items (from an initial pool of 21 potential items that were constructed based on a review of over 300 research articles, 100 popular press articles, and a panel discussion) were identified based on standard criteria and the results of a statistical analysis and were then loaded on two obliquerotated factors (i.e., obsessive $\mathrm{CB}$ and impulsive buying). Afterward, the six-item RCBS was validated by 555 university staff members, while its second-order factor structure was reconfirmed by performing repeated confirmatory factor analyses (CFAs). The respondents were screened using a clinical screener, and those who obtained a composite index of 25 or above (Compulsive Buying Index $=6-54$ ), were classified as individuals with CBB. The cut-off validity was confirmed using the actual purchase data of online shoppers. Since then, RCBS has been translated to five (or more) languages and has been validated in both developed and developing countries (Byeon et al., 2017; He, Kukar-Kinney, \& Ridgway, 2018; Horváth, van Herk, \& Adigüzel, 2013; Leite et al., 2013; Maraz et al., 2015).

However, RCBS is yet to be comprehensively validated and adapted to the Chinese population. To fill such gap, this study aimed to adapt RCBS to the Chinese population in Hong Kong and perform a psychometric testing on the traditional Chinese version of this scale (see "Supplementary material").

\section{METHODS}

This two-phase methodological study employed a crosssectional design with repeated measures. Phase 1 aimed to translate the English version of RCBS into traditional Chinese (which is the most commonly used and comprehensible language for Chinese people around the world), examine its relevancy and comprehensibility, and evaluate the adequacy of its translation, whereas Phase 2 examined the psychometric properties of its traditional Chinese (RCBS-TC) version. Figure 1 illustrates the entire process of adaptation and validation.

\section{Phase 1: Translation of RCBS}

Forward and backward translation. Two independent translators used Brislin's (1986) model of forward and backward translation to translate RCBS from its source language (SL, i.e., English) to the target language (TL, i.e., traditional Chinese). The TL version was reviewed by a Chinese monolingual reviewer (a university student) for ambiguous wordings. The research team then modified the identified ambiguities. A bilingual linguistic expert (a $\mathrm{PhD}$ graduate in the field of linguistics and translation) compared the backtranslated version (BT; translated by a psychiatric nursing professor) with the SL version to examine its linguistic congruence and cultural relevancy, and the research team subsequently discussed the translation incongruences or difficulties encountered by the expert, if any. The aforementioned process was repeated until the SL and BT reached maximum agreement.

Content and face validation. For content validation, six healthcare and social science professionals (including psychiatric nurses and academic experts in psychology and sociology) examined the relevancy of RCBS-TC using a 4-point scale (i.e., $1=$ not relevant, 2 = somewhat relevant, $3=$ quite relevant, and $4=$ highly relevant) (Polit $\&$ Beck, 2006). Those professionals who gave ratings less than 3 were asked to provide feedback. The content validity index (CVI), which indicates the proportion of responses that agree with the relevancy of the scale, was computed based on the mean ratings given by experts that gave ratings of 3 or 4. The scale-level [CVI on average (CVI/AVE)] and itemlevel CVIs (I-CVIs) are considered satisfactory when they have values of 0.80 or above (Polit \& Beck, 2006; Portney \& Watkins, 2009). 
Phase 1: Translation of RCBS

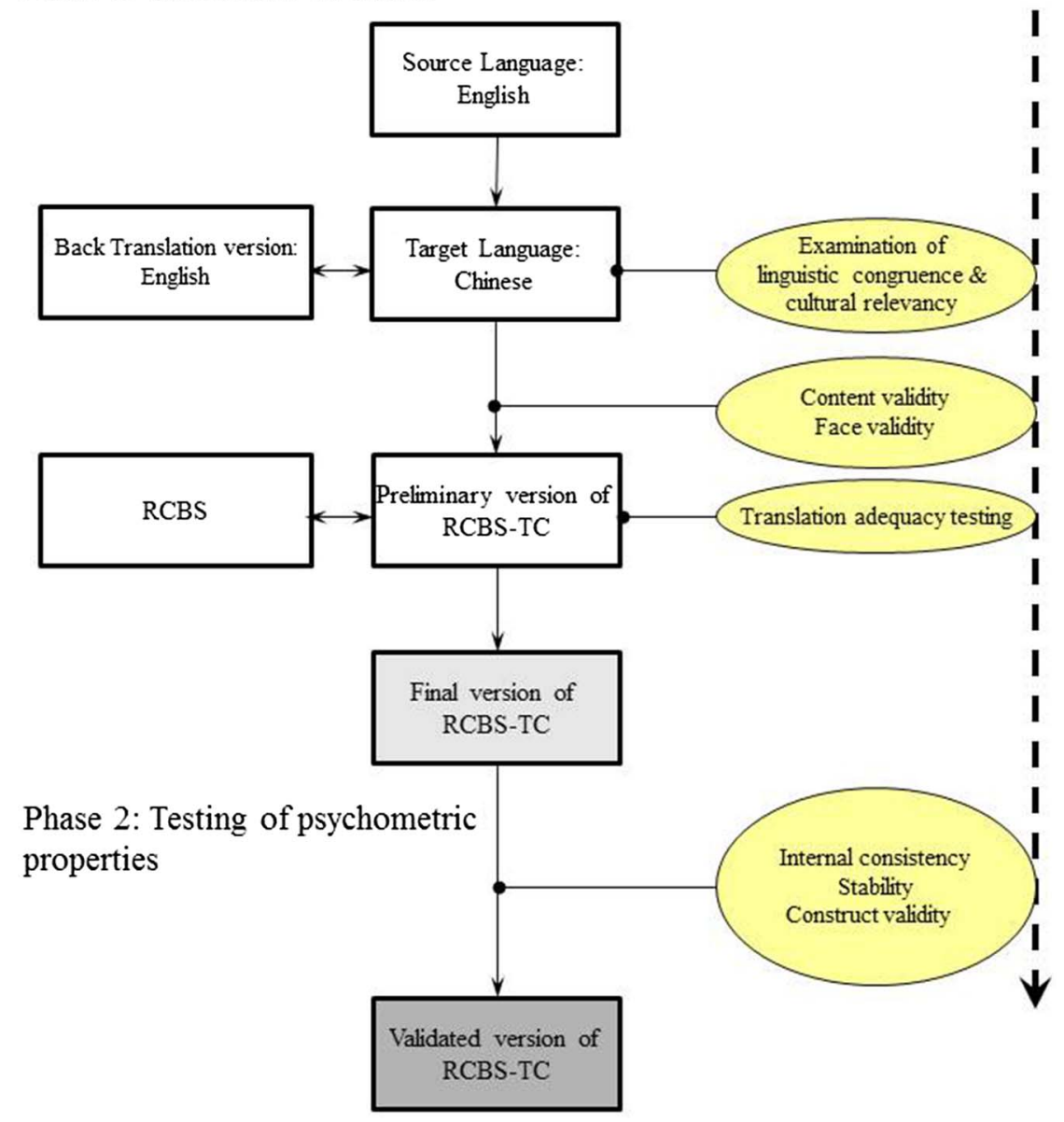

Figure 1. Flow diagram for the process of translation and validation

Face validation was performed to assess the comprehensibility of the RCBS-TC items to the general public and to ensure the applicability of this scale as a self-administered instrument. A purposive sample of 20 male/female, highly/ less educated, and young/old adults were recruited for the validation. A sample size of 20 was regarded by other methodological studies as sufficient in detecting ambiguous items (Lam, 2018; Lam et al., 2017). These participants were invited to review the scale for its comprehensibility (i.e., rated on a "yes/no" nominal scale) (Portney \& Watkins, 2009) and to rephrase each item to improve its interpretability (i.e., the researcher rated the respondents' answer on a 4-point Likert scale; Lam, 2018). The former method was conventionally adopted in other studies for face validation (Portney \& Watkins, 2009), whereas the latter method was deemed to have higher sensitivity and specificity in identifying problematic items compared with the former (Lam, 2018). If necessary, the participants suggested appropriate wordings and sentence styles for the items. Afterward, a preliminary version of RCBS-TC was developed.

Translation adequacy testing. Translation adequacy testing or cross-language testing is a stringent method for examining translation equivalence (Jones, 1987). The translation adequacy of RCBS and RCBS-TC was tested by recruiting a convenience sample of 62 undergraduate students and university staff members from a local university in
Hong Kong. These participants were selected for their ability to understand the items in both RCBS and RCBSTC. These participants first responded to RCBS before responding to RCBS-TC 2 weeks later. Each participant was indexed with an eight-digit code (a combination of their initials, student/staff identity numbers, and mobile phone numbers) for internal matching purposes and to ensure their anonymity. The equivalence between RCBS and RCBS-TC was computed by comparing the two sets of scores. An intraclass correlation coefficient (ICC) greater than 0.75 indicates a good translation equivalence (Portney \& Watkins, 2009).

\section{Phase 2: Psychometric testing of RCBS-TC}

A cross-sectional and correlation design with repeated measures was employed for the psychometric testing or RCBS-TC. After examining the content and face validity of RCBS and RCBS-TC in Phase 1, the other psychometric properties (i.e., internal consistency, test-retest reliability, and construct validity) were comprehensively evaluated in Phase 2. The participants were recruited from the general public in three districts of Hong Kong, namely, Kowloon, Hong Kong Island, and New Territories, which had a fair mix of people with different backgrounds. A research assistant invited pedestrians to complete self-administrated questionnaires (including demographic questionnaires and 
RBCS-TC). The paper-and-pencil method was used for the data collection. The sample size was 900, which was regarded "very good" to "excellent" for CFA (Tabachnick \& Fidell, 2007) and appropriate for psychometric testing.

Reliability. The internal consistency of RCBS-TS was examined using Cronbach's $\alpha$ statistics (where $\alpha \geq .70$ indicates a satisfactory result) and the corrected item-total correlation coefficient (where $r \geq 0.30$ indicates a homogenous item) (Portney \& Watkins, 2009), whereas its stability was tested by examining its test-retest reliability over a 2-week period. Given that samples recruited from the general public cannot be used for assessing test-retest reliability, a convenience sample of 62 university students was invited to answer the first questionnaire (T1) and the second questionnaire 2 weeks later (T2). The data collected from each student were used to match their T1 and T2 responses. Following previous studies (Lam et al., 2017), a self-generated code (i.e., a combination of student identity numbers and mobile numbers) was used to match the anonymous $\mathrm{T} 1$ and $\mathrm{T} 2$ responses. A sample size of 62 is suggested by a published formula [where expected ICC $=$ $0.80,95 \%$ confidence interval $(\mathrm{CI})$ for $\mathrm{ICC}=0.20$, and $20 \%$ attrition rate] (Giraudeau \& Mary, 2001). The ICC (where $\geq 0.75$ indicates a satisfactory result) was used to compare the T1 and T2 scores and to measure the stability of the scale (Portney \& Watkins, 2009).

Validity. Construct validity was established by examining the factorial structure of RCBS-TC. CFA was performed to examine the degree of fitness of the data in a hypothesized model (i.e., second-order two-factor model) and to determine the internal structure of RCBS-TC. Correlation matrices were used in the analyses, and the maximum likelihood estimation procedure was used to conduct each analysis. Goodness-of-fit measures, including the $\chi^{2} /$ degree of freedom ratio $\left(\chi^{2} / d f\right)$, normed fit index (NFI), comparative fit index (CFI), incremental fit index (IFI), and root mean square error of approximation (RMSEA), were used to assess the model fit. The above goodness-of-fit measures were previously reported by the developer (Ridgway et al., 2008). The aforementioned indicates have goodness-of-fit criteria of $\chi^{2} / d f<5.00$ (Chen \& Wang, 2010; Hair, Black, Babin, Anderson, \& Tatham, 2010), NFI, CFI, and IFI > 0.90, and RMSEA $<0.08$ (Byrne, 2009; Chen \& Wang, 2010).

\section{Ethics}

Ethical approval was sought from the ethical committee of a local university and the collaborative organization. The research team reproduced and translated RCBS with the permission of its developers (Ridgway et al., 2008). Informed consent was obtained from the participants through appropriate methods (i.e., verbal consent for the general public participants recruited in railway stations and written consent for the university students recruited in their campuses).

\section{RESULTS}

\section{Phase 1 results}

The RCBS was translated from English to traditional Chinese. The Chinese monolingual reviewer did not report any ambiguity in the preliminary TL version. Table 1 presents the comments (e.g., translation errors or encountered difficulties) of the reviewer regarding the SL and preliminary BT versions of RCBS. A linguistic expert confirmed the linguistic congruence and relevancy of both the SL and BT. According to his comments, the stem meanings of the items were maintained in the translation.

According to the six healthcare and social science professionals, RCBS-TC had a satisfactory relevancy as reflected in its CVI/AVE of $97.2 \%$ and I-CVI of $83.3 \%$ $100 \%$. For face validation, 20 participants (of which $60 \%$ were female) aged from 18 to 61 years and with primary school to master's degree education commented that the items in RCBS-TC were brief and comprehensible. Furthermore, all items were correctly interpreted and hence RCBS-TC had $100 \%$ comprehensibility as well as interpretability. To test translation adequacy, 62 participants responded to the English and traditional Chinese versions of RBCS within a 2-week interval. The ICC was equal to $0.858(95 \% \mathrm{CI}=0.774-0.912, p<.001)$.

\section{Phase 2 results}

A total of 921 participants completed the questionnaires. The responses from 100 participants were discarded because of missing data for RCBS-TC items $(n=23)$ and acquiescence responses (i.e., referring to the tendency of subjects to give a response regardless of the content of the item) $(n=$ $77)$, thereby leaving 821 data for the analysis $(57.5 \%$ female, $59.1 \%$ single, $61.0 \%$ with tertiary education, and $41.0 \%$ with monthly income between 1,283 and 2,564 USD). Table 2 presents the demographic characteristics of the participants. The Cronbach's $\alpha$ of RCBS was .88, whereas those of the subscales for obsessive $\mathrm{CB}$ and impulsive buying were .79 and .87 , respectively. The corrected item-total correlation coefficients ranged from 0.61 to 0.78 , thereby indicating the satisfactory homogeneity of the items in the scale. RCBS-TC was then administrated in 98 university students twice in a 2-week interval. Sixty-one of these students voluntarily completed the questionnaires twice (response rate $=62.2 \%$ ). The ICC was equal to 0.82 (95\% CI $=0.71-0.89)$, thereby indicating the satisfactory stability of RCBS-TC. Concerning the demographic difference of those attrition cases, there is no significant difference of gender between participants who completed the RCBSTC twice $(n=61)$ and once $(n=37)\left(\chi^{2}=2.03, p=.119\right)$.

Face and content validation was performed in Phase 1, and CFA was performed in Phase 2 to establish the construct validity of RCBS-TC. The CFA results indicated that all paths were significantly loaded to two hypothesized secondorder subconstructs (range of loadings $=0.73-0.88$ ), and that the factor loadings of all items were greater than 0.40 . The goodness-of-fit indices demonstrated a marginal data model fit $\left(\chi^{2} / d f=15.66, \mathrm{CFI}=0.96, \mathrm{NFI}=0.95\right.$, IFI $=0.96$, and RMSEA $=0.134)$ regardless of the trials on both firstand second-order models. Based on the modification indices of the covariances, two pairs of error terms with the largest modification indices (i.e., items 5 and 6, and items 1 and 2) were covaried (Gaskin, 2012). The corrected model demonstrated acceptable goodness-of-fit indices $\left(\chi^{2} / d f=7.51\right.$, $\mathrm{CFI}=0.99$, NFI $=0.98, \mathrm{IFI}=0.99$, and $\mathrm{RMSEA}=0.089$ ) 
Lam et al.

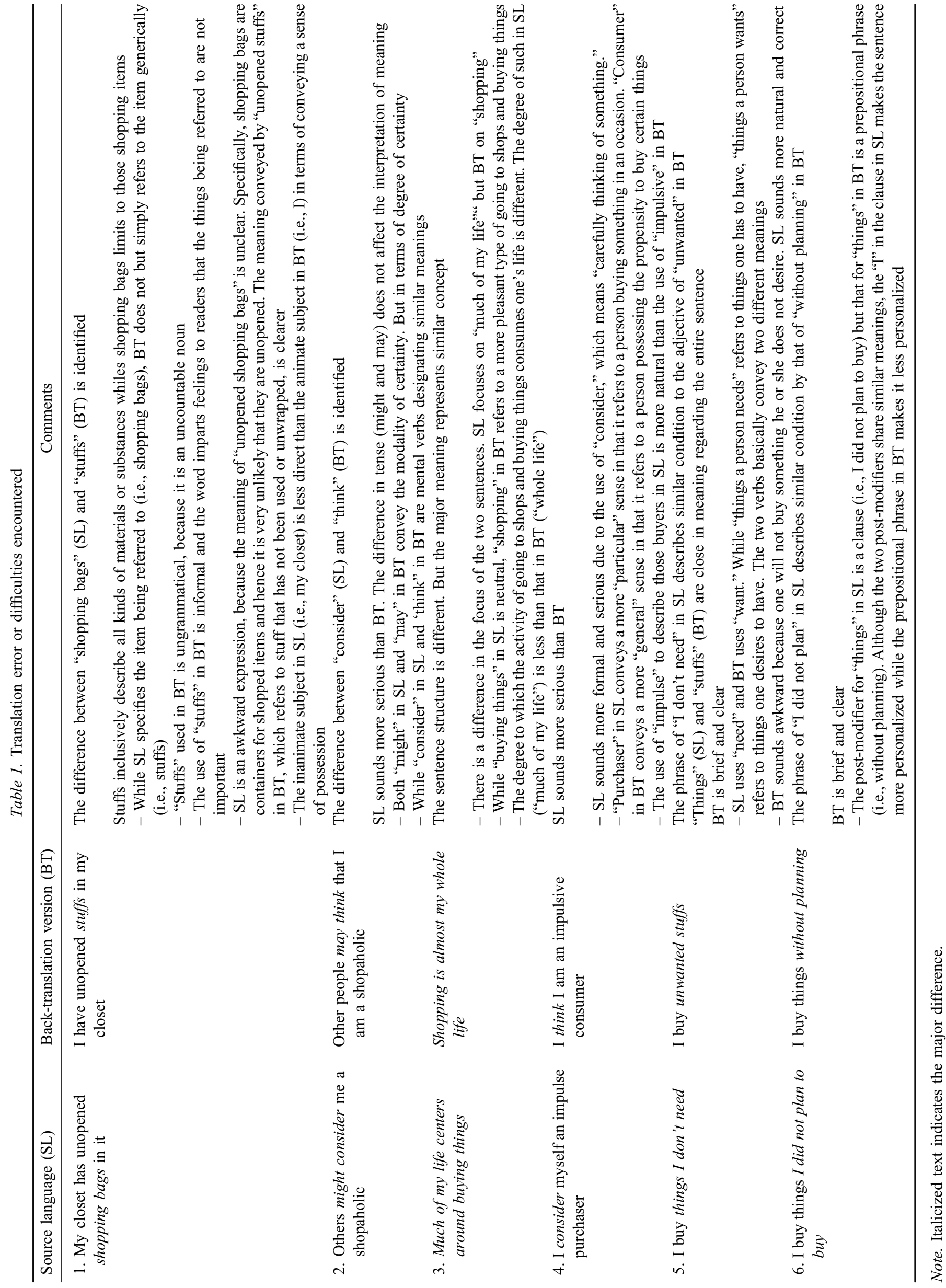


Table 2. Demographic characteristics of participants $(N=821)$

\begin{tabular}{|c|c|c|}
\hline Demographic characteristics & Frequency & Percentage \\
\hline \multicolumn{3}{|l|}{ Age range } \\
\hline $18-29$ & 368 & 44.8 \\
\hline $30-39$ & 179 & 21.8 \\
\hline $40-49$ & 114 & 13.9 \\
\hline $50-59$ & 123 & 15.0 \\
\hline$>60$ & 36 & 4.4 \\
\hline Missing & 1 & 0.1 \\
\hline \multicolumn{3}{|l|}{ Gender } \\
\hline Male & 344 & 42.0 \\
\hline Female & 471 & 57.5 \\
\hline Missing & 6 & 0.6 \\
\hline \multicolumn{3}{|l|}{ Marital status } \\
\hline Single & 485 & 59.1 \\
\hline Married/co-habit & 335 & 40.8 \\
\hline Missing & 1 & 0.1 \\
\hline \multicolumn{3}{|l|}{ Education background } \\
\hline Primary school or below & 56 & 6.8 \\
\hline Secondary school & 212 & 25.8 \\
\hline Tertiary school & 501 & 61.0 \\
\hline Master degree or above & 51 & 6.2 \\
\hline Missing & 1 & 0.1 \\
\hline \multicolumn{3}{|l|}{ Income range ${ }^{\mathrm{a}}$} \\
\hline $\begin{array}{l}\text { Less than USD } 1,282 \\
(\text { HKD 10,000) }\end{array}$ & 175 & 21.3 \\
\hline $\begin{array}{l}\text { USD } 1,283-2,564 \\
(\text { HKD } 10,001-20,000)\end{array}$ & 337 & 41.0 \\
\hline $\begin{array}{l}\text { USD } 2,565-5,128 \\
\text { (HKD } 20,001-40,000)\end{array}$ & 211 & 25.7 \\
\hline $\begin{array}{l}\text { USD 5,129-7,692 } \\
\text { (HKD 40,001-60,000) }\end{array}$ & 73 & 8.9 \\
\hline$>$ USD 7,693 (HKD 60,001) & 24 & 2.9 \\
\hline Missing & 1 & 0.1 \\
\hline
\end{tabular}

Note. USD: US dollar; HKD: Hong Kong dollar.

${ }^{a}$ USD-HKD exchange rate is based on 1-7.8 in general.

as well as significant path loadings in the first-order twofactor model. Table 3 summarizes the results of the psychometric testing of RCBS-TC, whereas Figure 2 lists the parameter estimations and factor loadings of each item to the hypothesized subconstructs of RCBS-TC.

\section{DISCUSSION}

\section{Psychometric properties of RCBS-TC}

RCBS was satisfactorily adapted to the Chinese population by performing a stringent translation procedure and validating its translation adequacy. The scale also showed a satisfactory internal consistency as reflected by an optimal Cronbach's $\alpha$ at both the scale and subscale levels (heterogeneous items in the scale for $\alpha \leq .70$ and overredundant items in the scale for $\alpha \geq .90$ ) (Portney \& Watkins, 2009). These findings are consistent with those of previous studies (Ridgway et al., 2008). The homogeneity of the items was further validated through the corrected itemtotal correlation. The correlation coefficient of each item was over 0.30 , thereby indicating that each item had a satisfactory homogeneity in their respective subscales (Portney \& Watkins, 2009). This result contributes to our understanding of the homogeneity of the items in RCBS-TC.

The ICC was used to evaluate the stability of RCBS-TC using the 2-week test-retest reliability method. High attrition rates reduced the value of ICC (Polit, 2014). The current response rate was $62.2 \%$ (i.e., $37.8 \%$ attrition rate), which was slightly high and hence the ICC of RCBS-TC was also likely to be underestimated. The high attrition rate may be normal for a volunteer-based participation in classroom setting, because some university students were absent or left their classes early (based on their attendance records) and gave incomplete responses to some RCBS-TC items or did not respond to the questionnaires twice, thereby increasing the attrition rate. Using ICC to test the stability of the scale was appropriate (Portney \& Watkins, 2009), because this approach "overrode the advantages against Pearson product-moment correlation in simultaneously assessing both correlation strength and concordance of the test scores" (Lam, 2015, p. 377).

CFA was regarded as the most appropriate method for examining the hypothesized relationships among the underlying latent and observable variables that comprise the internal structure of RCBS-TC (Portney \& Watkins, 2009). The CFA indicated that using a first-order two-factor model of RCBS-TC was more acceptable in Chinese population. Unlike some previous studies, CFA was calculated based on the small samples with similar characteristics, such as university students or staff members. The current CFA results were computed based on large-scale data $(N>800)$ that were collected from the general public with diverse demographic backgrounds, thereby enhancing the generalizability of these results.

Two goodness-of-fit indices of the current factor model need to be examined further. For instance, the value of $\chi^{2} / d f$ was exceedingly high $(>5.0)$ in the model (Chen \& Wang, 2010; Hair et al., 2010). Given that $\chi^{2}$ is sensitive to kurtosis distributions (Kenny, 2015), the endorsement frequencies of items $1,2,4$, and 6 had moderate kurtosis values of -0.912 , $-0.551,-0.892$, and -0.739 , respectively (data not shown in the "Results" section). Coincidentally, the $d f$ in the corrected first-order model was only 6 , which was deemed very small in value. Therefore, with an inflated $\chi^{2}$ and a small value of $d f$, this ratio $\left(\chi^{2} / d f\right)$ might be inflated as well. Furthermore, RMSEA was computed based on the non-centrality parameter for representing the absolute measure of fit, while its computational formula heavily depends on $d f$ and sample size (Byrne, 2009; Chen \& Wang, 2010; Hair et al., 2010). Indeed, those models with a small $d f$ can have artificially large RMSEA values (Kenny, Kaniskan, \& McCoach, 2015). Thus, with a small $d f(d f=6)$ in the current model, it was justified that there was an overestimation of the RMSEA value.

\section{Applicability of RCBS-TC}

The results of this study contribute to the findings of extant literature on the applicability of RCBS in various cultural and national groups (Byeon et al., 2017; Horváth et al., 2013; Leite et al., 2013; Maraz et al., 2015; Ridgway et al., 2008). RCBS and RCBS-TC are useful epidemiological instruments for examining the prevalence of $\mathrm{CBB}$. 
Table 3. Reliability and validity of the RCBS with previously published results

\begin{tabular}{|c|c|c|c|c|}
\hline & \multicolumn{3}{|c|}{ The current study } & \multirow{2}{*}{$\begin{array}{l}\text { Previous studies }^{\mathrm{a}} \\
\text { Results }\end{array}$} \\
\hline & Methods & Statistic methods & Results & \\
\hline \multicolumn{5}{|l|}{ Reliability } \\
\hline \multirow[t]{2}{*}{ 1. Internal consistency } & Cronbach's method & Cronbach's $\alpha$ statistic & $\begin{array}{l}\alpha \text { of scale }=.88 \\
\alpha \text { of subscales }=.79-.87\end{array}$ & $\begin{array}{l}\alpha=.81-.84 \\
\alpha \text { of subscales }=.75-.84\end{array}$ \\
\hline & $\begin{array}{l}\text { Corrected item-total } \\
\text { correlation }\end{array}$ & $\begin{array}{l}\text { Person moment- } \\
\text { product correlation } \\
\text { coefficient }\end{array}$ & $\begin{array}{l}\text { Corrected item-total } \\
\text { correlation }=0.61-0.78\end{array}$ & NA \\
\hline 2. Stability & $\begin{array}{l}\text { 2-week test-retest } \\
\text { reliability }\end{array}$ & $\begin{array}{l}\text { Intraclass correlation } \\
\text { coefficient (ICC) }\end{array}$ & $\begin{array}{l}r=.82, p<.001 \\
95 \% \mathrm{CI}=0.71-0.89\end{array}$ & NA \\
\hline \multicolumn{5}{|l|}{ Validity } \\
\hline 1. Face validity & $\begin{array}{l}\text { Review by target } \\
\text { population }^{c}\end{array}$ & $\begin{array}{l}\text { Frequency and } \\
\text { percentage }\end{array}$ & $\begin{array}{l}100 \% \\
\text { comprehensibility and } \\
\text { interpretability }\end{array}$ & NA \\
\hline 2. Content validity & $\begin{array}{l}\text { Review by expert } \\
\text { panel }\end{array}$ & $\begin{array}{l}\text { Content validity index } \\
\text { (CVI) }\end{array}$ & $\begin{array}{c}\mathrm{I}-\mathrm{CVI}=0.83-1.00 \\
\mathrm{CVI} / \mathrm{AVE}=0.97\end{array}$ & NA \\
\hline 3. Construct validity & Factor analysis & $\begin{array}{l}\text { Confirmatory factor } \\
\text { analysis }\end{array}$ & $\begin{array}{l}\chi^{2} / d f=7.51, \text { CFI }=0.99 \\
\text { NFI }=0.98, \text { IFI }=0.99, \\
\text { RMSEA }=0.089 . \\
\text { (first-order CFA model) }\end{array}$ & $\begin{array}{l}\text { Sample: } 352 \text { undergraduate } \\
\text { students in USA } \\
\chi^{2}(8)=11.00, \mathrm{CFI}=1.00, \\
\text { NFI }=0.99, \mathrm{IFI}=1.00, \\
\text { RMSEA }=0.03 \text {. } \\
\text { (second-order CFA model) } \\
\text { Sample: } 555 \text { university staff } \\
\text { in USA } \\
\chi^{2}(8)=37.86, \mathrm{CFI}=0.97, \\
\text { NFI }=0.97, \mathrm{IFI}=0.97, \\
\text { RMSEA }=0.08 . \\
\text { (second-order CFA model) }\end{array}$ \\
\hline
\end{tabular}

Note. CI: confidence interval; I-CVI: item-level content validity index; CVI/AVE: scale-level content validity index on average; NFI: normed fit index; CFI: comparative fit index; IFI: incremental fit index; RMSEA: root mean square error of approximation; CFA: confirmatory factor analysis.

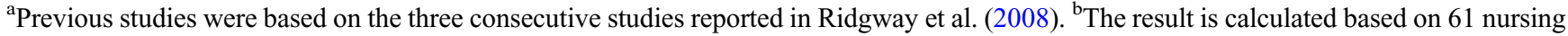
students. ${ }^{\mathrm{c}}$ The result is calculated based on 20 general public (age ranged from 18 to 72 ).

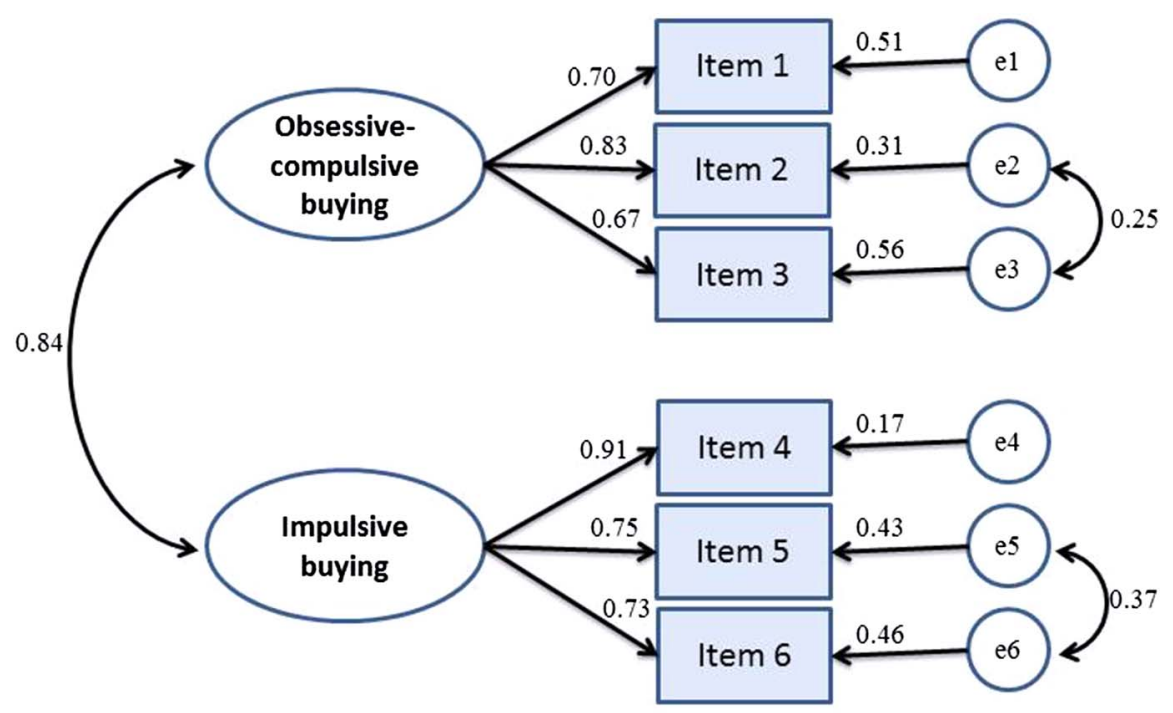

Figure 2. First-order confirmatory factor analysis model of Richmond Compulsive Buying Scale traditional Chinese version (RCBS-TC)

The six-item RCBS, which takes less than a minute to complete, can be used as a practical screening tool for identifying people with CBB. The self-administrated or self-reported nature of RCBS also enables the use of various methods for data collection, such as web-based surveys or mobile applications. RCBS-TC can also help researchers 
conduct population-based and multicountry studies at the national and international scales, respectively.

\section{Limitations and recommendations}

Several limitations of this study warrant further discussion. First, the developers of RCBS suggested a cut-off value of 25 for distinguishing compulsive buyers from noncompulsive ones (Ridgway et al., 2008). The optimal cutoff value of a screening tool is determined based on the receiver-operating characteristic curve, which allows the comparison of a range of scores (obtained from the screening tool) with their respective sensitivity and specificity against a recognized gold standard (Portney \& Watkins, 2009). In the healthcare discipline, such gold standard likely pertains to the diagnosis of healthcare professionals (Lang \& Secic, 2006), for example, physician (Lam et al., 2017; Lam, Lee, \& Yu, 2014) or nurse (Lam, Wong, \& Woo, 2010). However, in this work, the proposed cut-off value for RCBS-TC was not reexamined in Chinese population. The research team found that soliciting the medical diagnoses of doctors from all 921 community participants was difficult because of budget and time constraints. Therefore, the applicability of the mentioned cut-off value for the Chinese population must be revalidated in future studies.

Second, given that the English and foreign language versions of RCBS have been validated, a web-based survey could be adopted to collect a large number of data from various areas. However, limited studies have directly investigated the reliability and agreement between traditional interviews (e.g., paper-and-pencil questionnaires) and web-based surveys even though the latter has been recommended by epidemiological experts (Van Gelder, Bretveld, \& Roeleveld, 2010) and has been examined in several empirical comparison studies of consumer data (Szolnoki \& Hoffmann, 2013). This work adopted the paper-andpencil data collection method and did not verify reliability and agreement between traditional paper-and-pencil and web-based methods for validating RCBS-TC. Therefore, the reliability coefficients of traditional and web-based data collection methods must be compared in future research.

Regardless of these limitations, the statistical results demonstrated that RCBS was satisfactorily translated to traditional Chinese. This study provides sufficient evidence that RCBS-TC can be used to measure the CCB of the Chinese population.

Funding sources: This work was partially supported by the School of Science and Technology Unit Fund, The Open University of Hong Kong, Hong Kong (grant number: ST-17/18-1), and S. Living Campaign 2017, Wofoo Community Service Network, Wofoo Social Enterprises, Hong Kong.

Authors' contribution: SCL: development of the idea, project supervision, data analysis, and drafting of the manuscript. ZSLC: data collection and literature review. ACYC: data collection and analysis. WWCW: review of the manuscript. JY: review of the manuscript.

Conflict of interest: The authors declare no conflicts of interest.

Acknowledgements: The authors would like to thank the participants for their contributions to this study. They would also like to thank Eliza Yi-ni Wong, Ching-yuk Hon, Rochelle Tzs-wai Tang, Holly Hoi-tung Lam, Ming Tsang, and Lena Lok-ki Sung for their assistance in the data collection and inputs. They are grateful to Dr. Danny Chung-hong Leung, Dr. Chloe Chit-ning Li, and Dr. Fiona Wing-ki Tang for their inputs to Phase 1 study as well as Dr. Heping He for his critical comments on translation and manuscript.

\section{REFERENCES}

Billieux, J., Rochat, L., Rebetez, M. M. L., \& Van der Linden, M. (2008). Are all facets of impulsivity related to self-reported compulsive buying behavior? Personality and Individual Differences, 44(6), 1432-1442. doi:10.1016/j.paid.2007.12.011

Black, D. W. (2007). A review of compulsive buying disorder. World Psychiatry, 6, 14-18.

Brislin, R. W. (1986). The wording and translation of research instrument. In W. J. Lonner \& J. W. Berry (Eds.), Field methods in cross-cultural research (pp. 137-164). Beverly Hills, CA: Sage.

Byeon, G. H., Kim, R., Han, J. H., Ko, Y. M., Roh, S., \& Lee, T. K. (2017). Reliability and validity of the Korean version of Richmond Compulsive Buying Scale. Journal of Korean Neuropsychiatric Association, 56, 35-44. doi:10.4306/ jknpa.2017.56.1.35

Byrne, B. M. (2009). Structural equation modeling with AMOS basic concepts, applications, and programming. New York, NY: Routledge.

Chen, K. Y., \& Wang, Z. H. (2010). Advanced statistical analysis using SPSS and AMOS. Taiwan: Wunan Book Co.

Christenson, G. A., Faber, R. J., de Zwaan, M., Raymond, N. C., Specker, S. M., Ekern, M. D., Mackenzie, T. B., Crosby, R. D., Crow, S. J., Eckert, E. D., Mussell, M. P., \& Mitchell, J. E. (1994). Compulsive buying: Descriptive characteristics and psychiatric comorbidity. The Journal of Clinical Psychiatry, $55,5-11$.

Everitt, B. J., \& Robbins, T. W. (2016). Drug addiction: Updating actions to habits to compulsions ten years on. Annual Review of Psychology, 67(1), 23-50. doi:10.1146/annurevpsych-122414-033457

Gaskin, J. (2012). Confirmatory factor analysis. Retrieved from http:// statwiki.kolobkreations.com/index.php?title=Confirmatory Factor_Analysis/. Accessed on: February 8, 2018.

Giraudeau, B., \& Mary, J. Y. (2001). Planning a reproducibility study: How many subjects and how many replicates per subject for an expected width of the 95 per cent confidence interval of the intraclass correlation coefficient. Statistics in Medicine, 20(21), 3205-3214. doi:10.1002/sim.935 
Hair, J., Black, W., Babin, B. Y. A., Anderson, R., \& Tatham, R. (2010). Multivariate data analysis: A global perspective. Upper Saddle River, NJ: Pearson Prentice Hall.

He, H., Kukar-Kinney, M., \& Ridgway, N. M. (2018). Compulsive buying in China: Measurement, prevalence, and online drivers. Journal of Business Research, 91, 28-39. doi:10.1016/j. jbusres.2018.05.023

Horváth, C., van Herk, H., \& Adigüzel, F. (2013). Cultural aspects of compulsive buying in emerging and developed economies: A cross cultural study in compulsive buying. Organizations \& Markets in Emerging Economies, 4, 8-24.

Jones, E. (1987). Translation of quantitative measures for use in cross-cultural research. Nursing Research, 36(5), 324-327. doi:10.1097/00006199-198709000-00017

Kenny, D. A. (2015). Measuring model fit. Structural equation modeling. Retrieved from http://davidakenny.net/cm/fit.htm. Accessed on: March 23, 2018.

Kenny, D. A., Kaniskan, B., \& McCoach, D. B. (2015). The performance of RMSEA in models with small degrees of freedom. Sociological Methods \& Research, 44(3), 486-507. doi:10.1177/0049124114543236

Koob, G. F., \& Volkow, N. D. (2016). Neurobiology of addiction: A neurocircuitry analysis. The Lancet Psychiatry, 3(8), 760-773. doi:10.1016/S2215-0366(16)00104-8

Koran, L. M., Faber, R. J., Aboujaoude, E., Large, M. D., \& Serpe, R. T. (2006). Estimated prevalence of compulsive buying behavior in the United States. American Journal of Psychiatry, 163(10), 1806-1812. doi:10.1176/ajp.2006.163.10.1806

Lam, C. (2015). Development and validation of a quality of life instrument for older Chinese people in residential care homes. (Doctoral dissertation). The Chinese University of Hong Kong, Hong Kong. Available from ProQuest Dissertations Publishing. (UMI No.10297281)

Lam, S. C. (2018). Sensitivity and specificity of face validation in determining the comprehensibility of older people on quality of life items. Journal of the American Geriatrics Society, 66(Suppl. 2), S52.

Lam, S. C., Lee, D. T., \& Yu, D. S. (2014). Establishing cutoff values for the Simplified Barthel Index in elderly adults in residential care homes. Journal of the American Geriatrics Society, 62(3), 575-577. doi:10.1111/jgs.12716

Lam, S. C., Wong, Y. Y., \& Woo, J. (2010). Reliability and validity of the Abbreviated Mental Test (Hong Kong version) in residential care homes. Journal of the American Geriatrics Society, 58(11), 2255-2257. doi:10.1111/j.1532-5415.2010. 03129.x

Lam, S. C., Yeung, C. C. Y., Chan, J. H. M., Lam, D. W. C., Lam, A. H. Y., Annesi-Maesano, I., \& Bousquet, J. (2017). Adaptation of the score for allergic rhinitis in the Chinese population: Psychometric properties and diagnostic accuracy. International Archives of Allergy and Immunology, 173(4), 213-224. doi:10.1159/000477727

Lang, T. A., \& Secic, M. (2006). How to report statistics in medicine: Annotated guidelines for authors, editors and reviewers (2nd ed.). Philadelphia, PA: ACP Press.

Leite, P., Rangé, B., Kukar-Kinney, M., Ridgway, N., Monroe, K., Ribas, R., Jr., Landeira Fernandez, J., Nardi, A. E., \& Silva, A. (2013). Cross-cultural adaptation, validation and reliability of the Brazilian version of the Richmond Compulsive Buying Scale. Revista Brasileira de Psiquiatria, 35(1), 38-43. doi:10. 1016/j.rbp.2012.10.004

Li, S., Unger, A., \& Bi, C. (2014). Different facets of compulsive buying among Chinese students. Journal of Behavioral Addictions, 3(4), 238-245. doi:10.1556/JBA.3.2014.4.5

Lo, H. Y., \& Harvey, N. (2014). Compulsive buying: Obsessive acquisition, collecting or hoarding? International Journal of Mental Health and Addiction, 12(4), 453-469. doi:10.1007/ s11469-014-9477-2

Maraz, A., Eisinger, A., Hende, B., Urbán, R., Paksi, B., Kun, B., Kökönyei, G., Griffiths, M. D., \& Demetrovics, Z. (2015). Measuring compulsive buying behaviour: Psychometric validity of three different scales and prevalence in the general population and in shopping centres. Psychiatry Research, 225(3), 326-334. doi:10.1016/j.psychres.2014. 11.080

Maraz, A., Griffiths, M. D., \& Demetrovics, Z. (2016). The prevalence of compulsive buying: A meta-analysis. Addiction, 111(3), 408-419. doi:10.1111/add.13223

Mueller, A., Mitchell, J. E., Crosby, R. D., Gefeller, O., Faber, R. J., Martin, A., Bleich, S., Glaesmer, H., Exner, C., \& de Zwaan, M. (2010). Estimated prevalence of compulsive buying in Germany and its association with sociodemographic characteristics and depressive symptoms. Psychiatry Research, 180(2-3), 137-142. doi:10.1016/j.psychres.2009.12.001

Otero-López, J. M., \& Villardefrancos, E. (2014). Prevalence, sociodemographic factors, psychological distress, and coping strategies related to compulsive buying: A cross sectional study in Galicia, Spain. BMC Psychiatry, 14(1), 101. doi:10.1186/ 1471-244X-14-101

Paula, J. J., Costa, D. S., Oliveira, F., Alves, J. O., Passos, L. R., \& Malloy-Diniz, L. F. (2015). Impulsivity and compulsive buying are associated in a non-clinical sample: An evidence for the compulsivity-impulsivity continuum? Revista Brasileira de Psiquiatria, 37(3), 242-244. doi:10.1590/1516-4446-2014-1644

Polit, D. F. (2014). Getting serious about test-retest reliability: A critique of retest research and some recommendations. Quality of Life Research, 23(6), 1713-1720. doi:10.1007/s11136-0140632-9

Polit, D. F., \& Beck, C. T. (2006). The content validity index: Are you sure you know what's being reported? Critique and recommendations. Research in Nursing \& Health, 29(5), 489-497. doi:10.1002/nur.20147

Portney, L. G., \& Watkins, M. P. (2009). Foundations of clinical research: Applications to practice. Upper Saddle River, NJ: Pearson/Prentice Hall.

Ridgway, N., Kukar-Kinney, M., \& Monroe, K. (2008). An expanded conceptualization and a new measure of compulsive buying. Journal of Consumer Research, 35(4), 622-639. doi:10.1086/591108

Rose, S., \& Dhandayudham, A. (2014). Towards an understanding of Internet-based problem shopping behaviour: The concept of online shopping addiction and its proposed predictors. Journal of Behavioral Addiction, 3, 83-89. doi:10.1556/ JBA.3.2014.003

Starcke, K., Schlereth, B., Domass, D., Schöler, T., \& Brand, M. (2013). Cue reactivity towards shopping cues in female 
participants. Journal of Behavioral Addiction, 2, 17-22. doi:10.1556/JBA.1.2012.012

Szolnoki, G., \& Hoffmann, D. (2013). Online, face-to-face and telephone surveys - Comparing different sampling methods in wine consumer research. Wine Economics \& Policy, 2(2), 57-66. doi:10.1016/j.wep.2013.10.001

Tabachnick, B. G., \& Fidell, L. S. (2007). Using multivariate statistics. Boston, MA: Allyn \& Bacon/Pearson Education.

Van Gelder, M. M., Bretveld, R. W., \& Roeleveld, N. (2010). Web-based questionnaires: The future in epidemiology?
American Journal of Epidemiology, 172(11), 1292-1298. doi:10.1093/aje/kwq291

Wang, C. C., \& Yang, H. W. (2008). Passion for online shopping: The influence of personality and compulsive buying. Social Behavior and Personality, 36(5), 693-706. doi:10.2224/ sbp.2008.36.5.693

Yi, S. (2013). Heterogeneity of compulsive buyers based on impulsivity and compulsivity dimensions: A latent profile analytic approach. Psychiatry Research, 208(2), 174-182. doi:10.1016/j.psychres.2012.09.058 